\title{
Assessment of Depression, Anxiety, Stress, and Posttraumatic Stress Disorder in Iranian Medical Students during Outbreak COVID-19 Journal of Clinical Care and Skills
}

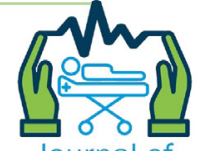

\section{ARTICLE INFO}

\section{Article Type}

Original Research

\section{Authors}

Najjar Mohiabadi A. ${ }^{1} B S C$,

Tajadini M. ${ }^{* 2} M S c$,

Seyedbagheri S.H. ${ }^{3} \mathrm{PhD}$,

Soltanmoradi Y. ${ }^{4} M S c$,

Sayadi A.R. ${ }^{5} P h D$

Harandi F. ${ }^{1} B S C$,

Jamali M. ${ }^{1} B S C$,

Kamrani M.H. ${ }^{1}$ BSc,

Khodadadi H. ${ }^{6} \mathrm{PhD}$

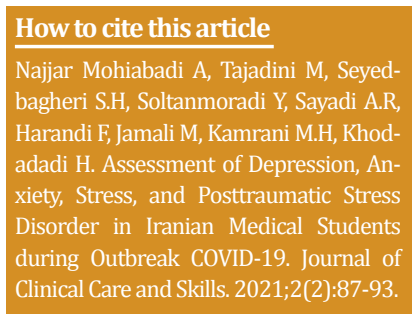

${ }^{1}$ Student Research Committee, Rafsanjan University of Medical Sciences, Rafsanjan, Iran ${ }^{2}$ Department of Anesthesiology, Faculty of Paramedical, Rafsanjan University of Medical Sciences, Rafsanjan, Iran

${ }^{34}$ Non-Communicable Diseases Research Center" and "Department of Pediatric Nursing, Nursing and Midwifery School", Rafsanjan University of Medical Sciences, Rafsanjan, Iran

${ }^{4}$ Department of Operating Room, Faculty of Paramedical, Rafsanjan University of Medical Sciences, Rafsanjan, Iran

${ }^{54}$ Department of Psychiatric Nursing, School of Nursing and Midwifery" and "Social Determinants of Health Research Center", Rafsanjan University of Medical Sciences, Rafsanjan, Iran ${ }^{64}$ Non-Communicable Diseases Research Center" and "Department of Health in Disasters and Emergencies, School of Health", Rafsanjan University of Medical Sciences, Rafsanjan, Iran

\section{*Correspondence}

Address: School of Nursing and Midwifery and Paramedical, Rafsanjan University of Medical Sciences, Rafsanjan, Iran. Postal Code: 7718796755

Phone: +98 (913) 3783962

Fax: +98 (34) 34258497

maryam.tajadiny@gmail.com

\section{Article History}

Received: December 23, 2020

Accepted: May 02, 2021

ePublished: June 20, 2021

\section{A B S T R A C T}

Aims With the announcement of the coronavirus pandemic by the World Health Organization, many people experienced many waves of panic. The disease was a major threat to individuals' physical and mental health because of the rapid spread and severe mortality. The continued development and changes in the educational process can affect student's mental health. This study aimed to investigate the frequency of posttraumatic stress disorder, anxiety, depression, and stress in students of Rafsanjan University of Medical Sciences during the coronavirus outbreak in 2020.

Materials \& Methods This cross-sectional descriptive study was conducted on students of Rafsanjan University of Medical Sciences. The sample size was 351 individuals selected by the convenience sampling method. Data were collected by DASS-21 and IES-R. Data were analyzed by SPSS18 using the chi-squared and Fisher's exact tests.

Findings The majority of students had moderate anxiety (33.6\%) and posttraumatic stress disorder (26.2\%). Depression (38.5\%) and stress (55.3\%) were not common in most students. Analysis of logistic regression showed a significant correlation between anxiety, stress, depression, and Posttraumatic stress disorder $(\mathrm{p}<0.05)$.

Conclusion The results suggest mental health problems among medical students. Therefore, it is recommended to implement psychological counseling programs to reduce these cases.

Keywords COVID-19; Students; Anxiety; Depression; Stress; Posttraumatic stress disory der

\section{I T A T I O N L I N KS}

[1] Novel Coronavirus disease 2019 ... [2] Worldometers.info ... [3] Mental health problems and social media ... [4] Mental health care for medical ... [5] Mental health services for older ... [6] Post-traumatic stress disorder ... [7] Mental health problems of Syrian ... [8] Validation of ICD-11 PTSD and complex ... [9] High risk of infection caused posttraumatic ... [10] Prevalence and predictors of PTSS ... [11] Magnitude and impact of comorbidity ... [12] The global burden of anxiety disorders ... [13] Effects of stress on immune function ... [14] Mental health status of doctors and nurses ... [15] The mental health of neurological ... [16] Mental health survey of medical staff in a tertiary ... [17] The psychological impact of the COVID-19 ... [18] PTSD in the DSM-5: Reply to Brewin ... [19] Work stress among Chinese nurses ... [20] Depression and other common mental ... [21] Depression in Iran: A systematic review ... [22] Generalized anxiety disorder, depressive ... [23] Psychological crisis intervention for ... [24] Middle east respiratory syndrome ... [25] Closure of universities due to Coronavirus ... [26] Impact of Sars-Cov-2 and its reverberation ... [27] Exploring the determinants of perceived ... [28] Assessing the pandemic potential of MERS ... [29] Assessment of depression, anxiety, and ... [30] Anxiety, depression and academic performance: A study ... [31] Prevalence of depression symptoms in U.S. ... [32] Anxiety and depression symptoms, and lack of ... [33] Post-traumatic stress symptoms among Iranian parents ... [34] Post-traumatic stress and growth among CPR survivors ... [35] Psychometric properties of the impact ... [36] The depression anxiety stress scales (DASS): Normative ... [37] Effects of applying progressive muscle relaxation ... [38] Depression and anxiety among Iranian medical... 


\section{Introduction}

China informed World Health Organization about unusual pneumonia at the beginning of the New Year 2020, a new type of coronavirus, and the cause of a new respiratory disease ${ }^{[1]}$. According to WHO, there have been 2.602.371 deaths from COVID-19 with more than 1.689 .692 confirmed infections in Iran since June 8, $2020^{[2]}$. It is noteworthy that these trends are increasing. The new coronavirus, scientifically known as SARS-CoV2, and the resulting disease, COVID-19, have caused great concern and panic among people worldwide [1].

The disease poses a great threat to life and physical health, especially the mental health of the public, and causes psychological problems because of the rapid spread of the COVID-19, severe infection, mortality in severe cases, and lack specific drugs [3]. The continued development and changes in the educational process are predicted to affect students' mental health $[4,5]$. Physical traumas can be treated and rehabilitated with medical care, but their sociopsychological pressures last for several weeks, months, years, or even throughout life [6].

Posttraumatic stress disorder (PTSD) means one's anxiety after any traumatic event [7]. PTSD consists of three symptoms: re-experiencing the trauma, avoiding traumatic reminders, and persistent feelings of current threat [8]. Lung Sun reported that the prevalence of PTSD in the main Chinese population during the corona epidemic was $4.6 \%$ [9]. Another study in China found that the rate of PTSD in Wuhan, China was $7 \%$ one month after the onset of the disease [10].

Anxiety and stress are common human responses, which can occur in men and women with different cultural backgrounds [11]. Anxiety has a protective function, and stress helps motivate people in practice. However, such responses can be detrimental when they exceed a certain time and level and negatively affect the quality of life and cause disability [12,13]. A study in China found that $16.0 \%$ of the nurses and physicians suffered from anxiety, and the prevalence of psychological distress was $15.9 \%$ [14]. Chen reported a mean anxiety score of 41.33 in nurses and physicians; women's anxiety was higher than that of men [15]. In a study in China, $23.04 \%$ of the health care staff reported anxiety [16]. Cao et al. found that $0.9 \%$ of the Chinese medical students suffered from severe anxiety, $2.7 \%$ of them suffered from moderate anxiety, and $21.3 \%$ reported mild anxiety [17]. High stress is a risk factor for many mental disorders such as depression [18]. A study at the COVID-19 Pneumonia hospitals in China found a stress rate of $39.27 \%$ [16]. Mo et al. studied job stress among nurses and reported a stress score of 39.91 [19].

Depression is a common mental disorder globally, which according to the World Health Organization, affected more than 300 million people worldwide in

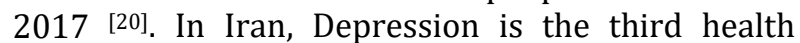

problem, major depressive disorder in women is in second place, and that of men is in seventh place [21]. Huang and Zhao reported a depression rate of $20.1 \%$ in China during the COVID-19 epidemic [22]. In a study, the mean depression score of the Chinese neurosurgeons and neurological nurses during the COVID-19 outbreak was 41.96, significantly associated with the age under 40 [15]. Liu also reported a depression rate of $34.6 \%$ in physicians and nurses [14].

Stress and anxiety caused by this pandemic, disability, fear caused by lockdown and isolation in the city, boredom, and irritability caused by a long stay at home greatly impact students [23] psychologically. They also have caused tremendous stress among students, which may have adverse effects on their learning and mental health [24, 25]. Many graduate students experience anxiety and panic caused by the countless consequences in their homework, seminars, and dissertation defense meeting. About half of the college students and about three-quarters of the university students are currently experiencing insecurity, fear, and mood loss [26]. Many journals have reviewed articles about hospital staff and residents. However, only a few studies have examined the psychological stress of health students during the prevalence of MERS-CoV [27]. MERS-CoV is associated with severe acute coronavirus syndrome (SARS-CoV), which appeared in 2002-03 [28]. Like health care staff, medical students were exposed to stressors during the outbreak, but this group is often overlooked despite the adverse effects on their academic achievement [24].

In pre-COVID-19 studies, a study was conducted in India in 2018 Showed that depressive, anxiety, and stress symptoms among medical students were respectively $32 \%, 40.1 \%$, and $43.8 \%{ }^{\text {[29]. }}$.

Another study in Portugal compared anxiety and depression among medical and non-medical students. The results showed that medical students showed more anxiety symptoms. They found that $23.6 \%$ of medical students had Anxiety symptoms [30]. In studies before and after COVID-19, a study in America's prevalence of depressive symptoms was assessed before and during the COVID-19 pandemic. The results showed that the prevalence of depressive symptoms during the COVID-19 pandemic was 3-fold higher than before [31].

Another study looked at the symptoms of anxiety and depression in people before and during the COVID-19 pandemic. The results showed that people were at greater risk of anxiety and depression symptoms during the COVID-19 pandemic [32].

Universities should provide guides for students to effectively and efficiently regulate emotions in emergencies and prevent losses caused by the crisis. Therefore, it is necessary to examine the mental state of the students in epidemics. Given the psychological 
effects of this pandemic on different people and the fact that no detailed studies have been done on the mental health of Iranian students, the present study aimed to determine the frequency of PTSD, anxiety, depression, and stress in medical students during the coronavirus outbreak.

\section{Materials and Methods}

This cross-sectional descriptive study was conducted on students of Rafsanjan University of Medical Sciences $(\mathrm{N}=390)$ during the outbreak of corona from March to April 2020. The sample size was considered to be 322 individuals based on type I error $\alpha=0.5$, $\mathrm{P}=0.7$, and $\mathrm{d}=0.05$ according to similar studies [14]. Twenty-eight individuals were added for certainty $(\mathrm{N}=350)$. Samples were selected by convenience sampling method from all faculties affiliated to Rafsanjan University of Medical Sciences. Samples were randomly selected based on the population covered by each faculty. Students who had a chronic physical illness, and known mental illness, and they were didn't complete the questionnaire up to $5 \%$, were excluded.

Demographic questionnaire, IES-R to measure PTSD, and depression anxiety stress scale (DASS-21) were used. Demographic information includes students' characteristics, age, gender, religion, number of semesters, number of semesters in bedside, internship period in hospital, economic status, sleep quality, living place, use of supplement medicines, living in the dormitory, fear of corona, corona testing, history of corona infection, family history of the corona, history of physical illness, and family history of mental illness. The IES-R is a 22-item self-report measure designed by Marmar \& Weis in 1997. The scale includes three dimensions: Intrusion (8 items), avoidance (8 items), and hyperarousal (6 items), which are graded on a 5-point Likert scale (0: Never experienced to 4: Experienced several times). Individuals with total scores $\geq$ of 33 have PTSD. In the study of Iranmanesh et al., the scale reliability coefficient was 0.87 [33]. In addition, Seyed Bagheri et al. have used this scale in their study and mentioned its reliability coefficient as 0.83 [34]. In the study of Creamer et al., the IES-R demonstrated high internal consistency (Cronbach's alpha=0.96) and about subscales intrusion: 0.94; avoidance: 0.87; hyperarousal: 0.91 was reported [35]. The DASS is a 21-item instrument for measuring anxiety, stress, and depression. Lovibond first proposed this scale in 1995 and confirmed its validity and reliability [36]. The final score for each of these dimensions is obtained by summing the scores of the relevant items. A four-point Likert scale was used ranging from 0 to 3, with options never, rarely, sometimes, always. Since this scale is a short form of the 42 -item one, the obtained scores are doubled. Scores above 14 would be considered moderate depression, scores above ten would be considered moderate anxiety, and scores above 19 would moderate stress. Ghaffari has used this scale and confirmed its validity and content validity. The reliability of the dimensions of depression, anxiety, and stress was $r=0.79, r=0.71$, and $r=0.74$, respectively, and the reliability of the whole instrument was $r=0.91$ [37].

The ethics committee of Rafsanjan University of Medical Sciences approved the study. Informed written consent was received from students. The necessary information about the research, its objectives, and importance was provided, and participants were ensured that their participation was voluntary and their information would be completely confidential. Face-to-face access to students was not possible due to the prevalence of corona and the university closure at the time of this study, so an online questionnaire was used. Questionnaire link was sent to students via SMS, and the research objectives were explained to them in the designed questionnaire; the participants were asked to put a checkmark on the section related to their consent, and then the relevant questions were provided to the students.

Data were analyzed by SPSS 18 using the mean \pm SD, Chi-squared and Fisher's exact for Compare ratios, and Logistic regression test for investigate the association between depression, stress and anxiety with PTSD.

\section{Findings}

The questionnaire was sent to 390 students and 351 students completed and returned the questionnaire. According to demographic results, the mean \pm SD age of the students was $21.17 \pm 1.6$, and the majority of participants were women $(65.5 \%), 20-25$ years old (55.8\%), and single (88.3\%). Most of them were living in urban regions $(92.8 \%)$.

According to the results, the mean \pm SD scores of depression, anxiety, stress, and PTSD were $11.92 \pm 7.76,11.23 \pm 5.8,14.76 \pm 7.08$, and 26.94 \pm 30.10 , respectively. Most of the students had moderate anxiety (33.6\%), and 26.2\% had PTSD. Depression $(38.5 \%)$ and stress $(55.3 \%)$ were not observed in the majority of students (Table 1 ).

Table 1) Frequency DASS and PTSD in Medical students (numbers in parenthesis are in percent)

\begin{tabular}{|c|c|c|c|c|c|}
\hline Variables & Normal & Mild & Medium & Severe & $\begin{array}{l}\text { Very } \\
\text { intense }\end{array}$ \\
\hline pression & $\begin{array}{l}135 \\
(38.5)\end{array}$ & $\begin{array}{l}65 \\
(18.5)\end{array}$ & & & $13(3.7)$ \\
\hline & $\begin{array}{l}100 \\
(28.5)\end{array}$ & $56(16)$ & & $\begin{array}{l}44 \\
(12.5)\end{array}$ & $33(9.4)$ \\
\hline Stress & $\begin{array}{l}194 \\
(55.3)\end{array}$ & $\begin{array}{l}68 \\
(19.4) \\
\end{array}$ & $\begin{array}{l}57 \\
(16.2) \\
\end{array}$ & $\begin{array}{l}28 \\
(8.0) \\
\end{array}$ & $4(1.1)$ \\
\hline
\end{tabular}

The chi-squared test showed that $60.0 \%$ of the individuals with poor sleep quality had severe depression, so depression was significantly associated with economic status, sleep quality, fear of 

corona, and family disease history. According to the chi-squared test, $40.0 \%$ of the individuals who had a very poor sleep quality or $50.6 \%$ of the individuals who had a family disease history had moderate anxiety, so anxiety was significantly associated with sleep quality, fear of corona, and family disease history. The results showed that the frequency of stress differs significantly only in terms of sleep quality and fear of corona (Table 2).

The results showed that $53.8 \%$ of the individuals who had a poor economic status or $67.6 \%$ of the individuals who had a poor sleep quality suffered from PTSD. Therefore, PTSD is also significantly associated with gender, economic status, sleep quality, physical illness, mental illness, and family illness history (Table 3 ).

Table 2) Frequency of depression, anxiety, and stress in students according to demographic characteristics (n=351)

\begin{tabular}{|c|c|c|c|c|c|c|c|c|c|}
\hline \multirow{2}{*}{ Variables } & & \multirow{2}{*}{ Normal } & \multirow{2}{*}{ Mild } & \multirow{2}{*}{ Medium } & \multirow{2}{*}{ Severe } & \multirow{2}{*}{ Very intense } & \multicolumn{3}{|c|}{ Chi-square test } \\
\hline & & & & & & & p & $\mathrm{X}^{2}$ & df \\
\hline \multicolumn{10}{|l|}{ Depression } \\
\hline \multirow{3}{*}{$\begin{array}{l}\text { Economic } \\
\text { status }\end{array}$} & Good & $1(1.1)$ & $4(4.5)$ & $24(27.0)$ & 15 (16.9) & $45(50.6)$ & \multirow{3}{*}{0.001} & \multirow{3}{*}{27.63} & \multirow{3}{*}{4} \\
\hline & Average & $9(3.6)$ & $27(10.8)$ & $77(31.0)$ & 48 (19.3) & $89(35.7)$ & & & \\
\hline & Bad & $3(23.1)$ & $3(23.1)$ & $4(30.7)$ & $2(15.4)$ & $1(7.7)$ & & & \\
\hline \multirow{4}{*}{ Sleep status } & good & $1(0.6)$ & $8(5.1)$ & $43(27.5)$ & $23(14.6)$ & $82(52.2)$ & \multirow{4}{*}{0.0001} & \multirow{4}{*}{62.92} & \multirow{4}{*}{4} \\
\hline & average & $7(4.5)$ & $16(10.3)$ & 46 (29.7) & $40(25.8)$ & $46(29.7)$ & & & \\
\hline & bad & 5 (14.7) & $7(20.6)$ & $14(41.2)$ & $2(5.9)$ & $6(17.6)$ & & & \\
\hline & Very bad & 0 & $3(60.0)$ & $1(20.0)$ & 0 & $1(20.0)$ & & & \\
\hline \multirow{2}{*}{ Fear corona } & Yes & $11(6.5)$ & $16(9.5)$ & 53 (31.6) & $32(19.0)$ & $56(33.7)$ & \multirow{2}{*}{0.043} & \multirow{2}{*}{9.82} & \multirow{2}{*}{4} \\
\hline & No & $2(1.1)$ & $18(9.9)$ & $51(27.5)$ & 33 (18.1) & $79(43.4)$ & & & \\
\hline \multirow{2}{*}{$\begin{array}{l}\text { Family COVID- } \\
19 \text { history }\end{array}$} & Yes & $4(4.6)$ & $7(8.0)$ & 39 (44.9) & $16(18.4)$ & $21(24.1)$ & \multirow{2}{*}{0.003} & \multirow{2}{*}{6.87} & \multirow{2}{*}{4} \\
\hline & No & $9(3.4)$ & $27(10.2)$ & $65(24.6)$ & $49(18.6)$ & $114(43.2)$ & & & \\
\hline \multicolumn{10}{|c|}{ Stress } \\
\hline \multirow{4}{*}{ Sleep status } & Good & $1(0.6)$ & $4(2.5)$ & $22(14.0)$ & $32(20.4)$ & $98(62.5)$ & \multirow{3}{*}{0.0001} & \multirow{4}{*}{45.37} & \multirow{4}{*}{4} \\
\hline & Average & $1(0.6)$ & $13(8.4)$ & $25(16.1)$ & 33 (21.3) & 83 (53.6) & & & \\
\hline & Bad & $2(5.9)$ & $10(29.4)$ & $8(23.5)$ & $3(8.8)$ & $11(32.4)$ & & & \\
\hline & Very bad & 0 & $1(20.0)$ & $2(40.0)$ & 0 & $2(40.0)$ & & & \\
\hline & Yes & $4(2.4)$ & $13(7.7)$ & $29(17.3)$ & $42(24.4)$ & $81(48.2)$ & 0.016 & & \\
\hline corona & No & 0 & $15(8.2)$ & $28(15.4)$ & $26(14.3)$ & $113(62.1)$ & & 12.25 & 4 \\
\hline Anxiety & & & & & & & & & \\
\hline & good & $7(4.5)$ & $14(8.9)$ & $49(31.2)$ & $33(21.0)$ & $54(34.4)$ & & & \\
\hline & average & $18(11.6)$ & $20(12.9)$ & 57 (36.8) & 21 (13.5) & $39(25.2)$ & & & \\
\hline Sleep status & bad & $8(23.5)$ & $8(23.5)$ & $10(29.5)$ & $2(5.9)$ & $6(17.6)$ & 0.002 & 31.58 & 4 \\
\hline & Very bad & 0 & $2(40.0)$ & $2(40.0)$ & 0 & $1(20.0)$ & & & \\
\hline & Yes & 25 (14.3) & $21(12.5)$ & 55 (32.7) & $21(12.5)$ & $47(28.0)$ & 0.035 & & \\
\hline Fear corona & No & $9(4.9)$ & $23(12.6)$ & 63 (34.6) & 34 (18.7) & $53(29.2)$ & & 10.34 & 4 \\
\hline Family disease & Yes & $5(5.7)$ & $7(8.0)$ & $44(50.7)$ & $7(8.0)$ & $24(27.6)$ & 0.001 & & 4 \\
\hline history & No & $28(10.6)$ & $37(14.0)$ & $74(28.0)$ & $49(18.6)$ & $76(28.8)$ & & 17.96 & 4 \\
\hline
\end{tabular}

Table 3) Frequency of PTSD in students according to demographic characteristics by chi-square test ( $\mathrm{n}=351$ )

\begin{tabular}{|c|c|c|c|c|}
\hline Variable & & Yes & No & p-value \\
\hline Gender & $\begin{array}{l}\text { man } \\
\text { woman }\end{array}$ & $\begin{array}{l}40(33.1) \\
52(22.6)\end{array}$ & $\begin{array}{l}81(66.9) \\
178(77.4)\end{array}$ & 0.034 \\
\hline $\begin{array}{l}\text { Economic } \\
\text { situation }\end{array}$ & $\begin{array}{l}\text { good } \\
\text { average } \\
\text { bad }\end{array}$ & $\begin{array}{l}19(21.3) \\
66(26.5) \\
7(53.8)\end{array}$ & $\begin{array}{l}70(78.7) \\
183(73.5) \\
6(46.2)\end{array}$ & 0.044 \\
\hline Sleep status & $\begin{array}{l}\text { good } \\
\text { average } \\
\text { bad } \\
\text { very bad }\end{array}$ & $\begin{array}{l}25(15.9) \\
41(26.5) \\
23(67.6) \\
3(60.0)\end{array}$ & $\begin{array}{l}132(84.1) \\
114(73.5) \\
11(32.4) \\
2(40.0)\end{array}$ & 0.0001 \\
\hline $\begin{array}{l}\text { Physical } \\
\text { History disease }\end{array}$ & $\begin{array}{l}\text { yes } \\
\text { no }\end{array}$ & $\begin{array}{l}14(46.7) \\
78(24.3)\end{array}$ & $\begin{array}{l}16(53.3) \\
243(75.7)\end{array}$ & 0.008 \\
\hline $\begin{array}{l}\text { Family history } \\
\text { disease }\end{array}$ & $\begin{array}{l}\text { yes } \\
\text { no }\end{array}$ & $\begin{array}{l}33(37.9) \\
59(22.3)\end{array}$ & $\begin{array}{l}54(62.1) \\
205(77.7)\end{array}$ & 0.004 \\
\hline $\begin{array}{l}\text { Psychology } \\
\text { History disease }\end{array}$ & $\begin{array}{l}\text { yes } \\
\text { no }\end{array}$ & $\begin{array}{l}5(62.5) \\
87(25.4)\end{array}$ & $\begin{array}{l}3(37.5) \\
256(74.6)\end{array}$ & $0.018^{*}$ \\
\hline
\end{tabular}

Logistic regression analysis was performed to determine the effect of independent variables on the dependent variable of PTSD; the variables of anxiety, depression, and stress were analyzed. The results of this analysis showed a significant correlation between anxiety $(p=0.026)$, depression $(p=0.0001)$, stress $(p=0.017)$, and PTSD. For every one-unit increase in the depression score, the risk for PTSD 
increases by 1.854 folds; for every one-unit increase in the anxiety score, the risk for PTSD increases by 1.41 folds, and every one-unit increase in the stress score, the risk for PTSD increases by 1.076 folds.

\section{Discussion}

This study showed that $26 \%$ of the students with moderate anxiety had PTSD, and most students were normal in terms of depression and stress.

The present study results showed that the majority of students did not report any signs of depression, but $13.4 \%$ of them suffered from severe and very severe depression. Huang and Zhao in China reported a depression rate of $20.1 \%$ during the COVID-19 epidemic [19]. The study was conducted on the Chinese people, which is consistent with the present study done on Iranian students. The mean \pm SD score of depression in all participants of the present study was 11.92 \pm 7.76 , and depression was significantly correlated with economic status, sleep quality, fear of corona, and family history of the disease. Chen et al. examined the mental health of psychiatrists and psychiatric nurses in China during the COVID-19 outbreak. The mean depression score was 41.96, and attitudes toward corona were not correlated with depressive symptoms [15]. The results of this study do not support the present study. In the present study, fear of corona is associated with depression, which was not mentioned by Chen. Liu reported a depression rate of $34.6 \%$ in physicians and nurses. Gender had no significant relationship with depression, and staff working in infectious disease hospitals had higher depression [14]. This study is consistent with the present study except for gender. In the present study, the mean \pm SD score of students' anxiety during the corona disease was $11.0 \pm 5.8$, and $33.7 \%$ of the participants had moderate anxiety, and $31.9 \%$ of them had severe and very severe anxiety. Chen reported a mean anxiety score of 41.33 in nurses and physicians, which was higher in women than in men. Symptoms of anxiety were higher in medical staff and younger nurses, and attitudes toward corona were not associated with depressive symptoms [15]. This study does not support the current study in terms of the factors affecting anxiety. The reason for this difference can be a different statistical population. Another study in China reported an anxiety rate of $23.04 \%$ in the health care staff [16]. This study is consistent with the present study, but the research population is different. Huang and Zhao examined generalized anxiety disorder, depressive symptoms, and sleep quality during the COVID-19 epidemic in China. The prevalence of anxiety disorders was reported to be $35.1 \%{ }^{[19]}$. The results of this study are consistent with that of the present study. A study in China reported an anxiety rate of $16 \%$ in nurses and physicians, and gender was not significantly associated with depression [14]. The results of this study do not support the present study except for gender. The possible reasons for this discrepancy may be related to the young participants in the present study. Cao et al. reported an anxiety rate of 0.9 percent, a moderate anxiety rate of 2.7 percent, and a mild anxiety disorder of $21.3 \%$ in Chinese medical students. In addition, living in urban areas and the stable family income were protective factors against anxiety, while gender was not a significant factor affecting anxiety [17]. Like the present study, gender was not a factor affecting anxiety. Unlike the current study, urban and rural living and economic status have been protective factors against anxiety. Huang et al. found that living in the city and close contact with COVID-19 patients caused more anxiety [19]. The results of this study are in line with that of the present study.

In the present study, the mean \pm SD stress score of students was $14.76 \pm 7.08,53 \%$ of the participants did not report any stress, and $35.7 \%$ reported mildmoderate stress. The results showed that sleep quality and fear of corona were among the factors associated with stress. Similar to the present study, a study was conducted to determine the mental health of medical staff at COVID-19 pneumonia hospitals in China, with a stress rate of $39.27 \%$ [16]. Mo et al. reported a job stress score of 39.91 among nurses [19]. In the present study, the mean \pm SD PTSD score was $26.94 \pm 30$, and $26 \%$ of the students had PTSD. Gender, sleep quality, physical illness, mental illness, and family illness influenced PTSD. Sun found that the prevalence of PTSD during the corona epidemic in China was 4.6 percent. The most important variables that played a role as risk factors included gender and poor sleep quality [9]. This study is inconsistent with the present study in terms of infection statistics, but it is consistent with the present study regarding gender and sleep quality. Liu et al. examined the prevalence of PTSD in several regions of China. PTSD was reported to be $7 \%$ in Wuhan, China, one month after the onset of the disease. Most people with PTSD were female, and better sleep quality reported less PTSD [10]. In the present study, gender and sleep quality are also factors influencing PTSD. However, males had a higher PTSD score in the present study. Zhang also reported increased PTSD and decreased sleep quality during the COVID-19 outbreak. He, like the present study, found a relationship between sleep quality and PTSD [9]. Huang et al. reported higher PTSD in women than in men [16].

In a study, Depression and Anxiety symptoms were assessed before and during the COVID-19 pandemic among Iranian Medical Students. Depression and anxiety in Iranian medical students before and after were not significantly different [38].

Since the present study was conducted only on medical students, it cannot be generalized to the entire student population and the general population. The self-report was another limitation of the study, 
so further studies on other social classes are recommended using interviewing and qualitative studies. Another limitation is convenience sampling. In the next studies, Random sampling must be done. The results of this study were provided to university officials to make the necessary decisions. Interventions such as psychologists, family counselors, and psychiatric nurses are recommended for high-risk students. Other solutions include holding counseling classes and training courses for students during crises.

\section{Conclusion}

The results suggest mental health problems among medical students.

Acknowledgments: The authors would like to thank all the students participating in this study and Rafsanjan University of Medical Sciences for their financial support.

Ethical Permissions: This study has a code of ethics no. IR.RUMS.REC.1399.016 from the ethics committee of the research deputy of Rafsanjan University of Medical Sciences.

Conflict of Interests: The authors declare no conflict of interests.

Authors' Contributions: Najjar Mohiabadi A. (First author), Original researcher (20\%); Tajadini M. (Second author), Discussion author (10\%); Seyedbagheri S.H. (Third author), Assistant researcher (10\%); Soltanmoradi Y. (Forth author), Introduction author (10\%); Sayadi A.R. (Fifth author), Statistical analyst (10\%); Harandi F. (Sixth author), Assistant researcher (10\%); Jamali M. (Seventh author), Assistant researcher (10\%); Kamrani M.H. (Eighth author), Methodologist (10\%); Khodadadi H. (Ninth author), Discussion author (10\%).

Funding/Sources: -

\section{References}

1- Tavakoli A, Vahdat K, Keshavarz M. Novel Coronavirus disease 2019 (COVID-19): An emerging infectious disease in the 21st century. Iran South Med J. 2020;22(6):432-50. [Persian]

2- Worldometers.info [Internet]. Unknown City: Worldometers; 2020 [Cited 2021 Mar. 06]. Available from: https://www.worldometers.info/coronavirus/country/ir an/.

3- Gao J, Zheng P, Jia Y, Chen H, Mao Y, Chen S, et al. Mental health problems and social media exposure during COVID19 outbreak. PLoS One. 2020;15(4):0231924.

4- Chen Q, Liang M, Li Y, Guo J, Fei D, Wang L, et al. Mental health care for medical staff in China during the COVID-19 outbreak. Lancet Psychiatry. 2020;7(4):15-6.

5- Yang Y, Li W, Zhang Q, Zhang L, Cheung T, Xiang YT. Mental health services for older adults in China during the COVID-19 outbreak. Lancet Psychiatry. 2020;7(4):19.

6- Wang CH, Tsay SL, Elaine Bond A. Post-traumatic stress disorder, depression, anxiety and quality of life in patients with traffic-related injuries. J Adv Nurs. 2005;52(1):22-30. 7- Yayan EH, Duken ME, Ozdemir AA, Celebioglu A. Mental health problems of Syrian refugee children: Post-traumatic stress, depression and anxiety. J Pediatr Nurs. 2020;51:2732

8- Haselgruber A, Solva K, Lueger-Schuster B. Validation of ICD-11 PTSD and complex PTSD in foster children using the international trauma questionnaire. Acta Psychiatr Scand. 2020;141(1):60-73.

9- Zhang F, Shang Z, Ma H, Jia Y, Sun L, Guo X, et al. High risk of infection caused posttraumatic stress symptoms in individuals with poor sleep quality: A study on influence of coronavirus disease (COVID-19) in China. medRxiv. 2020 March:1-13.

10- Liu N, Zhang F, Wei C, Jia Y, Shang Z, Sun L, et al. Prevalence and predictors of PTSS during COVID-19 outbreak in China hardest-hit areas: Gender differences matter. Psychiatry Res. 2020;287:112921.

11- Merikangas KR, Kalaydjian A. Magnitude and impact of comorbidity of mental disorders from epidemiologic surveys. Curr Opin Psychiatry. 2007;20(4):353-8.

12- Baxter AJ, Vos T, Scott KM, Ferrari AM, Whiteford HA. The global burden of anxiety disorders in 2010. Psychol Med. 2014;44(11):2363-74.

13- Dhabhar FS. Effects of stress on immune function: The good, the bad, and the beautiful. Immunol Res. 2014;58(23):193-210.

14- Liu Z, Han B, Jiang R, Huang Y, Ma C, Wen J, et al. Mental health status of doctors and nurses during COVID-19 epidemic in China. Lancet. 2020 Mar:1-10.

15- Ning X, Yu F, Huang Q, Li X, Luo Y, Huang Q, et al. The mental health of neurological doctors and nurses in Hunan province, China, during the initial stages of the COVID-19 outbreak. BMC Psychiatry. 2020;20(1):436.

16- Huang JZ, Han MF, Luo TD, Ren AK, Zhou XP. Mental health survey of medical staff in a tertiary infectious disease hospital for COVID-19. Zhonghua Lao Dong Wei Sheng Zhi Ye Bing Za Zhi. 2020;38(3):192-5. [Chinese] 17- Cao W, Fang Z, Hou G, Han M, Xu X, Dong J, et al. The psychological impact of the COVID-19 epidemic on college students in China. Psychiatry Res. 2020;287:112934.

18- Friedman MJ. PTSD in the DSM-5: Reply to Brewin (2013), Kilpatrick (2013), and Maercker and Perkonigg (2013). J Trauma Stress. 2013;26(5):567-9.

19- Mo Y, Deng L, Zhang L, Lang Q, Liao C, Wang N, et al. Work stress among Chinese nurses to support Wuhan in fighting against COVID-19 epidemic. J Nurs Manag. 2020;28(5):1002-9.

20- World health organization. Depression and other common mental disorders: Global health estimates [Internet]. Geneva: World Health Organization; 2017 [Cited 2020 Aug. 12]. Available from: https://www.who. int/mental_health/management/depression/prevalence_g lobal_health_estimates/en/.

21- Montazeri A, Mousavi SJ, Omidvari S, Tavousi M, Hashemi A, Rostami T. Depression in Iran: A systematic review of the literature (2000-2010). PAYESH. 2013;12(6):567-94. [Persian]

22- Huang Y, Zhao N. Generalized anxiety disorder, depressive symptoms and sleep quality during COVID-19 outbreak in China: A web-based cross-sectional survey. Psychiatry Res. 2020;288:112954.

23- Sun QH, Su Y. Psychological crisis intervention for college students during novel coronavirus infection epidemic. Psychiatry Res. 2020;289:113043.

24- Al-Rabiaah A, Temsah MH, Al-Eyadhay AA, Hasan GM, Al-Zamil F, Al-Subaie S, et al. Middle east respiratory syndrome-Corona virus (MERS-CoV) associated stress 


\section{3}

among medical students at a university teaching hospital in Saudi Arabia. J Infect Public Health. 2020;13(5):687-91.

25- Sahu P. Closure of universities due to Coronavirus disease 2019 (COVID-19): Impact on education and mental health of students and academic staff. Cureus. 2020;12(4):7541.

26- De Oliveira Araujo FJ, De Lima LSA, Cidade PIM, Nobre CB, Neto MLR. Impact of Sars-Cov-2 and its reverberation in global higher education and mental health. Psychiatry Res. 2020;288:112977.

27- Kim S, Kim S. Exploring the determinants of perceived risk of middle east respiratory syndrome (MERS) in Korea. Int J Environ Res Public Health. 2018;15(6):1168.

28- Bauch CT, Oraby T. Assessing the pandemic potential of MERS-CoV. Lancet. 2013;382(9893):662-4.

29- Taneja N, Sachdeva S, Dwivedi N. Assessment of depression, anxiety, and stress among medical students enrolled in a medical college of New Delhi, India. Indian J Soc Psychiatry. 2018;34(2):157-62.

30- De Sousa JM, Moreira CA, Telles-Correia D. Anxiety, depression and academic performance: A study amongst Portuguese medical students versus non-medical students. Acta Med Port. 2018;31(9):454-62.

31- Ettman CK, Abdalla SM, Cohen GH, Sampson L, Vivier PM, Galea S. Prevalence of depression symptoms in U.S. adults before and during the COVID-19 pandemic. JAMA Netw Open. 2020;3(9):2019686.

32- Van Der Velden PG, Contino C, Das M, Loon PV, Bosmans
Najjar Mohiabadi A. et al.

MWG. Anxiety and depression symptoms, and lack of emotional support among the general population before and during the COVID-19 pandemic: A prospective national study on prevalence and risk factors. J Affect Disord. 2020;277:540-8.

33- Iranmanesh S, Shamsi A, Dehghan M. Post-traumatic stress symptoms among Iranian parents of children during cancer treatment. Issues Ment Health Nurs. 2015;36(4):279-85.

34- Seyed Bagheri SH, Iranmanesh S, Rayyani M, Dehghan M, Tirgari B, Hosseini SH. Post-traumatic stress and growth among CPR survivors in the southeast of Iran. Int J Adolesc Med Health. 2018;32(3).

35- Creamer M, Bell R, Failla S. Psychometric properties of the impact of event scale-revised. Behav Res Ther. 2003;41(12):1489-96.

36- Crawford JR, Henry JD. The depression anxiety stress scales (DASS): Normative data and latent structure in a large non-clinical sample. Br J Clin Psychol. 2003;42(Pt 2):111-31.

37- Ghafari S, Ahmadi F, Nabavi M, Memarian R. Effects of applying progressive muscle relaxation technique on depression, anxiety and stress of multiple sclerosis patients in Iran national MS society. Res Med. 2008;32(1):45-53. [Persian]

38- Nakhostin-Ansari A, Sherafati A, Aghajani F, Khonji MS, Aghajani R, Shahmansouri N. Depression and anxiety among Iranian medical students during COVID-19 pandemic. Iran J Psychiatry. 2020;15(3):228-35. 